\title{
The Construction of National Value Chain and the Upgrading of China's Sporting Goods Manufacturing Industry Cluster under the Background of Globalization
}

\author{
Fan Teng, Geng Cong* \\ Institute of physical education and health, research center for physical education reform and development, College of \\ physical education, Henan University, Kaifeng, Henan, China \\ *Corresponding author.
}

\begin{abstract}
By using methods of literature, comparative analysis and logic analysis, this paper studies the obstacles and constraints faced by the value chain leaders in the process of functional upgrading of China's sporting goods manufacturing industry cluster under the global value chain environment. The upgrading practice of foreign industrial clusters shows that domestic enterprises can rely on the familiar local market and cultural background to form a strong national value chain (NVC), occupy the high-end links of the value chain, have domestic well-known brands, sales channels and other high-end links in the value chain, and then develop and spread gradually, occupy foreign markets with similar demand, establish a national value chain dominated by local companies as the "chain master", and finally, enter the European and American markets to establish a balanced value chain parallel to the dominance of international giants such as ADIDAS and NIKE, break through the status of being "captured" and "squeezed", and realize product functional upgrades.
\end{abstract}

Keywords: Globalization, national value chain, sporting goods manufacturing, industrial upgrading

\section{Introduction}

Since the reform and opening up, China's sporting goods companies have relied on low cost and resource advantages to embed the sporting goods global value chain (GVC) with original equipment manufacturer (OEM) as the starting point, and have achieved rapid development. However, embedding the global production system dominated by leading global companies (global international large-scale purchasers such as Nike, Adidas, or Wal-Mart) by the way of OEM makes enterprises stay at the low end of the global value chain, fall into "low-end locking" with low product added value and low profits. With the outbreak of the international financial crisis, the appreciation of the RMB, the rise in labor and raw material costs, and other factors that bring shocks to the sporting goods processing industry, small and medium-sized enterprises close down one after another, and the value of foreign trade exports has dropped significantly. The reason is that OEMs have strong external dependence, have no right to speak and price in the global value chain, and lack their own brand and independent innovation capabilities. Therefore, carrying out industrial upgrading, by constructing a national value chain with its own brand and marketing channels based on local advantages, is an important measure for China's sporting goods companies to get rid of the status of being "squeezed" and "captured" in the global value chain. By strengthening the cooperation and connection among enterprises, giving full play to their respective comparative advantages, extending the industrial chain, and relying on product brand advantages and the construction of their own sales channels to realize the docking with the global value chain, forming a national value chain dominated by local enterprises will have important practical significance for the upgrading of China's sporting goods industrial cluster.

\section{Embedding in the Global Value Chain and Integrating into the Governance Structure of the "Captured" GVC}

2.1 Embedding GVC to form a captive governance relationship

If China's sporting goods industry cluster is embedded in GVC, it must follow the basic rules of GVC, implement

ISSN: 0010-8189 
the requirements of the governor for product processing, meet a certain specification on product quality, and ship the products to the designated location within the specified time. The relationship between them is completely unequal, and the upgrade of China's sporting goods industry cluster will surely be restricted and hindered by the GVC governors. The export markets of China's sporting goods companies are mainly Europe and the United States. Adidas and Nike are the undisputed leaders and governors in the value chain. Chinese companies have a typical captured governance relationship with them.

\subsection{Negative Effects of Embedding GVC}

(1) Embedding GVC weakens the initiative of independent development. After China's sporting goods companies are embedded in GVC, the order from value chain governors is like a central nervous system that tightly controls the fate of OEM companies [1]. These companies are generally small in scale and do not have technical and financial support. They can only rely on the technology spillovers of large international purchasers and comply with their product requirements for processing production and delivery on time. Over time, such enterprises have given up the cultivation of advanced elements, succumbed to the control of GVC managers, and are captured at the low end of GVC positions.

(2) The embedding of GVC restrains the space for enterprises' industrial upgrade. Enterprises engaged in international subcontracting are easily locked in the low-end links of the industrial chain by value chain governors, and can only win by a large scale, low cost, and low price. When these companies upgrade their branding, marketing, research \& development and design functions, few companies can succeed.

(3) Enterprises engaged in international subcontracting need to dynamically introduce advanced foreign equipment. In order to meet the stringent requirements of foreign governments and consumers on product environment and quality, domestic OEM companies need to continuously introduce advanced foreign equipment for upgrading and transformation. The profits earned by companies are always used in the upgrading of production equipment, and there is no more capital investment used for product research \& development and brand building. The international OEM enterprises are always locked in the processing and production links, processing and producing products for the buyers, which poisons the innovative spirit and consciousness of the enterprise and leads the enterprise to a situation where it loses its independent innovation ability.

\section{Restrictive Factors of China's Sporting Goods Industrial Cluster Upgrading under the Background of GVC}

3.1 GVC governors implementing vertical control to block domestic industrial upgrading

(1) Technological advantage is a strategic asset for multinational companies to block the upgrading of domestic industrial clusters. Relying on their technological advantages in key areas, multinational companies obtain high profits. In order to maintain their own interests, they usually adopt strict control measures to prevent technological proliferation and spillover. For example, Nike adopts a single-center research \& development management mode, placing the technology center at the center of enterprise group's research and development to prevent technology spillover.

(2) Multinational companies implement brand control to ensure their monopoly position in GVC. Relying on capital and technological advantages, multinational companies usually establish joint ventures with well-known local brand companies, and hold the right of controlling the joint ventures to achieve control of well-known local brands. For example, after the Beijing Olympics, at the end of 2011, Belle International giants took a fancy to the potential of the post-Olympic market and acquired Shenzhen Leader Sporting Goods Co., Ltd., the largest sports brand agency in South China. In March of the following year, Adidas and Nike distributors were sold to Belle, indicating that the ambitions of Belle as an International oligarchs have become more and more obvious. However, the domestic sporting goods retail industry still has no absolute giants. Belle's recent series of mergers and 
acquisitions have revealed its intention to become an oligarch in the industry.

3.2 Weak innovation ability of industrial clusters easily leading to "lemon" phenomenon and resulting in low-level competition

(1) Sporting goods export-oriented enterprises embed GVC in the form of OEM, which has become an important carrier in the process of internationalization in this field, and quickly opened up the international market in a short period of time. OEM companies achieve product updates and technological progress mainly through learning and imitation, while long-term technical imitation will inevitably reduce the company's independent innovation capability, and lock OEM companies in the low-end link of GVC, such as the shoe burning incident in Elche, Spain. On September 17, 2004, nearly a thousand local shoe dealers and shoe factory workers in Elche organizedly gathered in the famous local ELCHE Industrial Park, calling on locals to "burn all the shoes that enter in this city " and shouting: "We want to eat! We want to survive! The Chinese get out" and other slogans. And they burned a container with Wenzhou shoes. In fact, this incident is only a small episode for my country's footwear industry to open up foreign markets. Chinese shoes are cheap and will certainly be resisted by the local footwear industry which is an inevitable competition in international trade. In order to enter the international market, some new exporters often use low-price strategies as the forerunner and do not pay attention to product quality. In the end, Chinese shoes wear a "low-price hat" in the international market. Lessons learned, the reason for the appearance of Spain's rejection is that we do not have a world-renowned brand, and the lack of a world-renowned brand is the biggest difficulty for Chinese shoes to compete in the international market.

(2) The independent innovation ability of enterprises in the cluster is not strong, and the enterprises imitate each other resulting in the "Lemon" phenomenon that using inferior as superior. Since most of the enterprises in the cluster are small and medium-sized enterprises with weak independent innovation ability, they often imitate each other, scamp work and stint material, use inferior as superior, and use fake goods as real goods, which ultimately destroys the reputation of the entire cluster. For example, China's Jinjiang sporting products exporting to Europe and the United States have been repeatedly sanctioned and anti-dumping restricted. Certainly, these countries are dissatisfied with the rise of China and adopt malicious retaliation. At the same time, there are also reasons of the decline in product quality and low price competition.

\subsection{Lagging behind of producer service development and rising of transaction costs within clusters}

From the perspective of the upgrading of the sporting goods industry structure, compared with the processing and manufacturing industry, the production service industry in the cluster lags behind in terms of service quality, service efficiency, and service cost [2]. In addition, the government's service level and finance, insurance, education and training, and information services are also obviously lagging behind, which restricts the development of industrial clusters in different aspects. It shows that the competitive advantage of China's sporting goods industrial cluster is only limited to the processing and manufacturing links. The lack of intermediary institutions for cluster development results in low operating efficiency and high transaction costs within the cluster, which restricts the transformation and upgrading of enterprises from processing and manufacturing to research \& development and sales.

In summary, under the background of globalization, China's sporting goods industry will not have long-term competitiveness if they rely on low-level factors to embed GVC in the international OEM mode and processing orders, they must carry out product functional upgrade and value chain upgrade. However, GVC governors will take measures such as acquiring the sales market, strengthening product brands, and changing product parameters to increase the barriers to entry of high added value such as improving research \& development and marketing channels, and do everything possible to prevent them from upgrading their product functions. Thus Chinese enterprises can realize the transformation and upgrading of the development of China's sporting goods industry to a high-end route by constructing a national value chain, a regional value chain and increasing the input of high-level factors. 


\section{Analysis of the Upgrading Path of Industrial Cluster from the Perspective of GVC}

Humphrey (American scholar, 2002) believes that the upgrading path of industrial cluster embedded in GVC is generally: process upgrading, product upgrading, function upgrading and chain upgrading. For the buyer-driven value chain of the sporting goods industry, its upgrade must follow a gradual upgrading mode of process - product - function - chain upgrading. Of course, if the industrial cluster achieves breakthrough results and rapidly improves its dynamic capabilities, it will be able to achieve unconventional leap-forward upgrades.

\subsection{Gradual upgrading mode}

The sporting goods industrial cluster is a buyer-driven value chain, and its upgrade must follow an upgrading path of technological process - product - function - chain upgrading. (1) Process upgrade. That is to use advanced machinery and equipment or improve production system to improve the efficiency of the manufacturing process, such as adopting a more efficient production line, shortening the delivery time or increasing the inventory turnover rate. (2) Product upgrade. That is to improve the original product or introduce new products to increase the added value of the unit product so that to surpass the opponent. (3) Function upgrade. That is to abandon the low value-added link and climb to the high value-added link. For example, companies climb from the manufacturing link to high additional links such as product research \& development and brand marketing. (4) Chain upgrade. That is to shift to other industries with higher added value.

\subsection{Leaping upgrade mode}

Leaping upgrade refers to the direct jump of industrial clusters from processing and production links at the low end of the value chain to high value-added links. This kind of mode has a relatively large degree of difficulty. Industrial clusters embedded in GVC must not only carry out a second venture to achieve market development and technological catch-up, but also avoid the low-end control and chase of GVC governors. At present, most export-oriented industrial clusters only have advantages in scale and manufacturing, and there is a large gap between them and foreign countries in high-end technology. Therefore, industrial clusters must carry out a second entrepreneurship, achieve technological innovation and market development, break through the constraints of GVC governors, and achieve high-end upgrades of industrial clusters.

4.3 Constructing a sporting goods national value chain (NVC) parallel to GVC to achieve a leaping upgrade of sporting goods industry

4.3.1 The construction of NVC - an effective way to realize the leaping upgrade of sporting goods industrial cluster In order to transform from a major sporting goods manufacturing country to a powerful country, China should formulate a strategy to break through from the "captured" GVC, and rebuild a national value chain parallel to GVC on the basis of GVC, from "Made in China" to "Created in China", from an insourcing relationship in the global value chain to an outsourcing relationship, from a peripheral dependency relationship to a self-centered control relationship, from the status of a worker to the position of the boss. The change of this relationship is a reform related to the future and destiny of China's sporting goods industry [9]. However, restructuring NVC is not about changing from export-oriented to import substitution, but on the basis of embedding GVC, reintegrating the industrial cycle system on which Chinese enterprises depend, reshaping the governing structure of NVC, and laying a solid foundation and development platform for industrial upgrading and the sustainable development of sporting goods[3]. The reconstruction of NVC is not to give up the existing international market share and demand, but to shift from relying on foreign markets to paying equal attention to both domestic and foreign markets, relying on the domestic market for branding, accepting orders from large foreign purchasers and competing with foreign companies through technology spillover and diffusion. Different from competing with foreign companies'direct export, it may not immediately touch the fundamental interests of large purchasers, so it will not be immediately chased by international value chain managers. Therefore, this strategy is acceptable and feasible for small and medium-sized enterprises with weaker domestic strength. 
4.3.2 China's sporting goods industrial cluster having the prerequisites for building a national value chain already The realization of functions or chain upgrades of China's sporting goods industrial clusters under GVC will be blocked or restricted by value chain governors. The construction of a national value chain parallel to GVC can not only apply the production and design capabilities accumulated in GVC to the domestic market, but also function upgrades through NVC can avoid the competition with GVC-led enterprises to a certain extent. In this way, domestic enterprises can transform from completely relying on foreign markets to paying equal attention to domestic and foreign markets, rely on the local market to build domestic well-known brands, and then gradually develop into international brands. Companies gradually improve the position in GVC through NVC, change the captured governance relationship, and break through the passive position in GVC.

(1) A number of sporting goods listed companies in china being able to act as the core enterprises in the national value chain

At present, there are a number of listed sporting equipment companies in the eastern coastal area of China owning research \& development design, brand and sales channels. After more than 30 years of rapid development, their management level and processing technology have been significantly improved, and a group of industrial workers have been created. Their products have a certain degree of popularity and influence in the country, and can assume the core enterprise and leading position of the national value chain. Major domestic brand manufacturers such as Li-Ning, Anta, and 361 have already begun to control the sporting goods value chain in the domestic market.

(2) The huge domestic market and the gradual increase in high-end demand laying a market foundation for building a national value chain

China has a vast territory, a large population, and a large potential demand, which provides space for enterprises to specialize in division of labor and production. The unbalanced development between the east and the west provides convenient conditions for the industrial gradient transfer. In addition, with the improvement of people's living standards and the increase of leisure time, people's awareness of fitness has increased, sporting consumption groups have increased year by year, and the high-end demand of sport enthusiasts has also increased significantly. This has laid a good foundation for sporting goods companies to build NVC.

(3) The unbalanced development between the east and the west in china laying the foundation for the establishment of eegional intra-industry division of labor relationship

Due to China's vast land, abundant resources and large population, the cost of land and labor in the western region is significantly lower than that in the eastern region, which has laid the foundation for the construction of the division of labor within the region. This is because each link of the value chain has different requirements for production factors, that is, reseearch \& development, design, marketing and other links have higher requirements for high-level factors such as capital, brand, and technology, while processing and production links have higher requirements for land, labor, and raw materials. The difference and multi-level nature of production factors in the eastern and western regions just meet the requirements of the regional industrial division of labor. Putting each link of the value chain in the region that best matches the factors of production, and giving full play to the comparative advantages of each region can maximize the overall resources.

\section{Countermeasures and Suggestions}

\subsection{Suggestions}

5.1.1 Enhancing the core competitiveness of domestic core enterprises and the governance capabilities of the national value chain

Through policy support and financial support for the research $\&$ development design, brand development and marketing channel construction of domestic core enterprises, it can help improve the competitiveness of local leading enterprises and the governance capabilities of the domestic value chain. At the same time, it is necessary to 
actively support small and medium-sized enterprises to take a professional development path, encourage them to cooperate with leading enterprises to jointly build a competitive advantage in the domestic value chain and achieve a win-win situation for enterprises in the value chain [4].

5.1.2 Establishing a regional cooperation mechanism to make the distribution of benefits of regional cooperation fair

The country must formulate plans that are conducive to the coordinated development of regional industries, build a mechanism for cooperation and mutual benefit among local governments, coordinate and steadily resolve conflicts and contradictions in the process of building a national value chain. In addition, the country should ensure the fairness of the profit distribution of inter-regional cooperation through payment transfer, and create conditions for the flow of resource factors. Local governments should avoid interfering with the cooperative production of cross-regional enterprises through administrative means, establish new thinking and new ideas for win-win cooperation among regions, and ensure the operation and production of cross-regional enterprises.

5.1.3 Core enterprises cultivating advanced production factors and striving to enter GVC from high-end

With the improvement of people's living standards and the growth of the sports population, the high-end demand for sporting goods has further increased. Therefore, core and leading companies should focus on exploring the domestic high-end market, increase research \& development investment, produce and sell more excellent products, increase the bargaining chips with multinational purchasers, strive to enter the high-end global value chain and realize the transformation from a captive governance mode to a balanced governance mode.

\subsection{Countermeasures}

5.2.1 Functional upgrades for markets in Latin America, ASEAN and other countries

Buyers in these regions are relatively scattered. The two parties have low dependence, and the power of both parties in the transaction is relatively balanced, and it is a market-based governance mode among the two. Moreover, because the consumer groups and demand levels in these countries are better connected with domestic suppliers, the opportunity to make the brand bigger and stronger, and realize the function and chain upgrade for this market can be seized.

5.2.2 Setting up trade barriers to restrict developed countries' products from entering the domestic market and appropriately protecting the domestic market

Appropriate protection of the domestic market is an indispensable condition for the development of national value chain in the early stage. The country appropriately restricts the import of foreign products through trade barriers, laying a foundation for the formation of a domestic product value chain and the realization of industrial upgrading. For example, in the process of upgrading the global value chain, Japanese companies restricted the import of foreign products to protect the upgrading of domestic products, and ultimately occupied the high value-added strategic link.

5.2.3 Adjusting the operating links of the value chain through industrial transfer

With the substantial increase in China's per capita income, the increase in the sports population, and the further expansion of the differentiation of sports consumption, a local advantage are provided for the construction of the domestic value chain. At the same time, Chinese enterprises can also take advantage of the familiar local market to occupy market network resources, integrate and coordinate the domestic consumption market, focus on the construction of brand management and sales channels, and occupy the high-end product value chain through overseas transfer and outsourcing of processing and production links to achieve product functional upgrades.

\section{Conclusion}

The impact of the US subprime crisis in 2008 highlighted the predicament of China's sporting goods industry being over-embedded in the global value chain leading to industrial upgrading and competitive advantages upgrading, and also made the significance of achieving industrial function upgrading through the construction of a national 
value chain more prominent. At present, the step-by-step transfer of the sporting goods industry to the central and western regions is a strategic consideration of the national industrial layout, an inevitable choice under the economic transformation situation, and also provides a good opportunity for local enterprises to build a national value chain. Therefore, domestic leading core companies must increase investment in channel construction, product research \& development and other high added value links, support small and medium-sized enterprises to take the development path of specialized production, encourage cooperation with core companies, create value chain advantages, and achieve product functional upgrades.

\section{References}

[1] Z.B. Liu, J.H. Zheng, et al., "China in terms of value: a new strategy of selective opening in the yangtze river delta," Beijing, People's University of China Press, 2012.

[2] Z.B. Liu, "Reconstructing the national value chain: transforming the development mode of China's manufacturing industry," Forums of World Economics and Politics, no. 4, pp. 1-9, 2011.

[3] L.Y. Hong, et al., "FDI, outsourcing and the trap of China's manufacturing upgrading-an analysis from the perspective of micro-production organization control," Industrial Economic Research, no. 5, pp. 16-19, 2013.

[4] J. Zhang, "Enterprise group research \& development management mode," 2007, http://pera.e-works.net.cn/document/200706/article645.htm 